\title{
CORRIGENDA
}

\section{Corrigendum: Cxorf6 is a causative gene for hypospadias}

Maki Fukami, Yuka Wada, Kanako Miyabayashi, Ichizo Nishino, Tomonobu Hasegawa, Giovanna Camerino, Christine Kretz, Anna Buj-Bello, Jocelyn Laporte, Gen Yamada, Ken-ichirou Morohashi \& Tsutomu Ogata

Nature Genetics 38, 1369-1371 (2006); published online 5 November; corrected after print 7 December 2006.

In the version of this article initially published, the name of the sixth author (Agneta Nordenskjöld) was missing. Agneta Nordenskjöld is in the Department of Molecular Medicine and Surgery, Karolinska University Hospital, Stockholm, Sweden. This error has been corrected in the HTML and PDF versions of the article. 